\title{
The usefulness of the somatosensory evoked potentials of the pudendal nerve in diagnosis of probable multiple sclerosis
}

\author{
$\mathrm{G} \mathrm{Sau}^{2}$, S Siracusano*,1, I Aiello ${ }^{2}$, G d'Aloia ${ }^{1}$, G Liguori $^{1}$, S Stener ${ }^{1}$, A Lissiani $^{1}$ and E Belgrano ${ }^{1}$ \\ ${ }^{1}$ Department of Urology, University of Trieste, Italy; ${ }^{2}$ Department of Neurology, University of Sassari, Italy
}

\begin{abstract}
Study design: The aim of the study was to evaluate the sensitivity of pSEP in patients affected by probable MS.

Objectives: Bladder dysfunction is the presenting symptom in $2 \%$ of patients affected by multiple sclerosis (MS) and may be present in up to $78 \%$ of them. Abnormalities of somatosensory evoked potentials of the pudendal nerve (pSEP) have been found by many authors in patients affected by clinically defined MS, but little is known of diagnostic reliability of pSEP in early stage of MS.

Methods: Sixteen patients, eleven females and five males, aged between 18 and 45 years old (mean age 28.9), affected by clinically probable MS, were studied. Six of them reported retention or urge incontinence. pSEP with P1 (P40) scalp wave was analyzed. All patients also underwent visual evoked potentials (VEP), SEP of median and tibial nerves (mSEP, tSEP), brainstem acoustic evoked potentials (BAEPs), MRI of the brain and cerebrospinal fluid (CSF) evaluation. Urodynamic study with simultaneous measurement of intravesical, intraurethral and abdominal pressures with external sphincter electromyography was performed.

Results: Abnormalities of the evoked potentials were found in all patients. Abnormalities of the pSEP were observed in all the symptomatic cases and in eight of the remaining ten patients; ten showed no responses from the scalp and four showed P1 increased latency. Urodynamic abnormalities were found in 12 patients and MRI showed demyelinating lesions in 13 patients and oligoclonal bands were found in eight of them.

Conclusion: pSEP can be worthwhile as part of the initial diagnostic evaluation in patients affected by MS. It provides information of diagnostic relevance and plays a role in screening patients for urodynamic testing, which, however, is more specific for detecting urethrovesical dysfunctions and preventing urological complications.
\end{abstract}

Keywords: multiple sclerosis; bladder dysfunction; somatosensory evoked potential (SEP); pudendal nerve

\section{Introduction}

Multiple sclerosis (MS) is a disabling neurologic disease usually affecting young adults. Urinary incontinence, retention and/or sexual impotence are the common disturbances in patients affected by multiple sclerosis. Bladder dysfunctions are the presenting symptom in $2 \%$ of patients and may be present in up to $78 \%$ of patients. ${ }^{1}$ In order to define the kind of bladder dysfunction in MS, many authors carried out urodynamic studies and observed three different patterns of abnormality: detrusor hyperreflexia, detrusor-sphincter dyssinergy and detrusor areflexia. $^{2-6}$ It has been suggested by pathological ${ }^{7}$ and MRI studies $^{1}$ that these abnormalities are due to the involvement of the spinal cord, particularly of the

*Correspondence: S Siracusano, MD, Department of Urology, University of Trieste, Ospedale di Cattinara, Strada di Fiume 447, 34100 Trieste, Italy cervical tract. Abnormalities of somatosensory evoked potential of the pudendal nerve have been found by many authors in patients affected by clinically defined MS with symptomatic bladder dysfunctions ${ }^{6,8-10}$ but little is known on the diagnostic reliability of pSEP in the early stage of MS. The aim of the present study was to evaluate the diagnostic sensitivity of pSEP in patients affected by probable MS and to correlate the neurophysiological findings with bladder functional abnormalities.

\section{Material and methods}

Sixteen patients, 11 females and 5 males, aged between 18 and 45 years (mean age 28.9), affected by clinically probable MS according to Poser's diagnostic criteria ${ }^{11}$ were studied. The patients were examined within 15 days of their admission to the Neurological clinic of 
the University of Sassari. The clinical data are shown in Table 1. Six patients reported retention or urge incontinence. None had signs or symptoms or peripheral neuropathy. The pSEP in men was recorded by stimulating the pudendal nerve with ring electrodes placed around the penis, with the cathode proximally and the anode $3 \mathrm{~cm}$ distally. In women a probe with the cathode on the clitoris and the anode $15 \mathrm{~mm}$ away was used. Subjects were examined in the supine position. Rectangular stimuli of $0.1 \mathrm{~ms}$ duration were delivered at $3 \mathrm{~Hz}$ frequency. The stimulus intensity was twice the individual sensory threshold. An active platinum-iridium needle electrode was placed on the scalp $2 \mathrm{~cm}$ behind $\mathrm{Cz}$ and reference electrodes were placed on the ear lobes. The amplifier bandpass was setted from $5 \mathrm{~Hz}-5 \mathrm{Khz}$, the analysis time was $100 \mathrm{~ms}$ and 1000 artifact-free responses were averaged twice. The p1 (P40) scalp wave was analyzed. pSEP was thought to be abnormal when the P1 wave was absent or the latency increased according to our normal values ${ }^{12}$ (Figures 1 and 2). In all patients, VEP, SEP of median and tibial nerves (mSEP, tSEP), BAEP and MRI of the brain were performed and CSF was studied to assess the presence of oligoclonal bands (OB). Urodynamic evaluation, including simultaneous measurement of intravesical, intraurethral and intraabdominal pressures, and external sphincter electromyography was also carried out.

\section{Results}

The results obtained on the 16 patients are summarized in Table 2 and Table 3. Abnormalities of the evoked potentials were found in all patients. VEP showed increased P100 latency in three patients with history or clinical signs of optic neuritis and in four of the 13 remaining patients. Absence or increased N20 latency was found in two of the six symptomatic patients and in three of the asymptomatic patients. tSEP was impaired in two of the four symptomatic and in three of the remaining cases. Abnormalities of the pSEP were observed in all the symptomatic cases and in eight of the remaining ten patients; ten showed no responses from the scalp and four showed P1 increased latency.

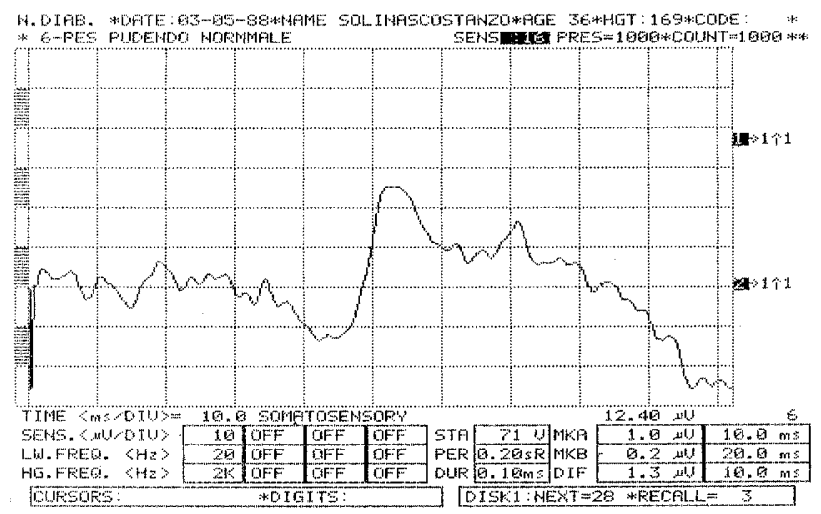

Figure 1 Normal pSEP

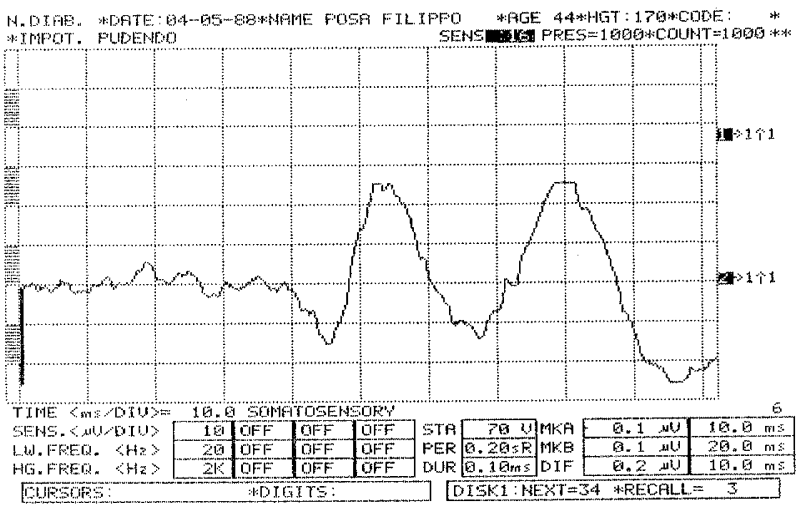

Figure 2 Pathological pSEP

Table 1 Clinical data

\begin{tabular}{|c|c|c|c|c|}
\hline Patient & Age & $\operatorname{Sex}$ & Symptoms at onset & Bladder dysfunction \\
\hline $1 \mathrm{FG}$ & 26 & $\mathrm{~F}$ & Diplopia & No \\
\hline $2 \mathrm{PS}$ & 22 & $\mathrm{~F}$ & Paresthesias of upper limb & No \\
\hline $3 \mathrm{SP}$ & 25 & $\mathrm{~F}$ & Monolateral hypoaesthesia of upper limb & No \\
\hline $4 \mathrm{SG}$ & 28 & M & Monolateral hypoaesthesia of upper limb & No \\
\hline $5 \mathrm{FL}$ & 24 & $\mathrm{~F}$ & Hemihypoaesthesia & No \\
\hline $6 \mathrm{MA}$ & 36 & $\mathrm{~F}$ & Hemiparesis and hemihypoaesthesia & No \\
\hline $7 \mathrm{SG}$ & 29 & M & Monolateral trigeminal hypoaesthesia & No \\
\hline $8 \mathrm{RF}$ & 22 & $\mathrm{~F}$ & Monolateral trigeminal hypoaesthesia & No \\
\hline 9 AR & 22 & $\mathrm{~F}$ & Monolateral hypoaesthesia of upper limb & Yes \\
\hline $10 \mathrm{MP}$ & 18 & M & Paresthesias of lower limbs and diplopia & No \\
\hline $11 \mathrm{PP}$ & 38 & $\mathrm{~F}$ & Tetraparesis and monolateral hypoaesthesia of upper limb & Yes \\
\hline $12 \mathrm{PG}$ & 29 & $\mathrm{~F}$ & Optic neuritis & Yes \\
\hline $13 \mathrm{CL}$ & 42 & $\mathrm{~F}$ & Hemiparesthesia & Yes \\
\hline $14 \mathrm{NV}$ & 35 & M & Monoparesis of lower limband paresthesia of upper limb & Yes \\
\hline $15 \mathrm{EA}$ & 46 & M & Paraparesis & No \\
\hline $16 \mathrm{IG}$ & 33 & $\mathrm{~F}$ & Optic neuritis & Yes \\
\hline
\end{tabular}


An increased III-V interpeak interval or the absence of the $\mathrm{V}$ wave of BAEP were found in four patients in spite of the absence of subjective and instrumental hearing impairment.

Urodynamic abnormalities were found in 12 patients: detrusor-sphincter dyssynergy was observed in seven patients (four symptom free and three affected by urge incontinence); four subjects, two asymptomatic and two with urge incontinence, showed detrusor hyperreflexia, while the remaining patient with retention showed detrusor areflexia. In the four remaining asymptomatic patients the urodynamic evaluation was normal. In the 12 patients with urodynamic impairment and in two of the four remaining patients pSEP were found to be abnormal.

MRI showed demyelinating lesions in 13 patients and oligoclonal bands were found in eight of them.

\section{Discussion}

MRI is suggested to be the most sensitive exam in the diagnosis of MS. ${ }^{13}$ The severity of the MRI abnormalities (number and size of lesions) does not always correlate with the duration of disease or the degree of disability. ${ }^{14}$ MRI showed demyelinating lesions in $81 \%$ of our patients. Evoked potentials may identify lesions in the different sensory pathways and play an important role as a diagnostic tool in MS. It is well known that the abnormality rate of multimodality evoked potentials increases with the duration of the disease and with clinical disability. ${ }^{15-19}$ A greater increase in VEP latency was found in patients with a greater disability rate, ${ }^{20}$ without relation between VEP delay and duration of the disease. ${ }^{21-23}$ BAEP and tSEP abnormality rates increase significantly with disease duration and clinical disability. ${ }^{24}$ BAEP have been found more frequently to be abnormal in patients with clinical signs of brainstem dysfunction. $^{18,24,25}$ Median nerve SEP correlate well with clinical disability. ${ }^{24}$ In previous studies a statistical correlation was found between detrusor hyperactivity or detrusor hypoactivity with disease duration, disability and neurophysiological findings. ${ }^{26}$ Cortical evoked potentials following stimulation of the pudendal nerve were delayed in a high percentage of MS patients with bladder dysfunction, ${ }^{27}$ however the real impairment rate of the pSEP is at present not well known in early stages of MS. Classical multimodality evoked potentials recorded in our patients showed an abnormality rate of $68.7 \%$. VEP was abnormal in $43.7 \%$, BAEP in $25 \%, \mathrm{mSEP}$ and tSEP in $31.2 \%$. The pSEP was found to be abnormal in $87.5 \%$ of our patients, showing a higher abnormality rate. Abnormalities of evoked potentials included the pSEP were found in $100 \%$ patients, and at least one asymptomatic lesion was observed in $87.5 \%$. The urodynamic study showed an abnormality rate of $75 \%$ and all the patients with urodynamic impairment showed pSEP pathology. Our findings confirm the frequent involvement of the urinary central pathway in MS. The pSEP actually is a non-conventional somatosensory evoked potential in the diagnosis of MS and there is no data from the literature about the correlation of the pSEP with the duration of the disease and with the disability, but our data indicates a high abnormality rate since the early stages of the disease. We can conclude that lower urinary tract abnormalities can be found in the majority of patients affected by MS, independently of

Table 2 Results

\begin{tabular}{|c|c|c|c|c|c|c|c|c|}
\hline Patient & $V E P$ & $B A E P$ & $m S E P$ & $t S E P$ & $p S E P$ & $\begin{array}{l}\text { Urodynamic } \\
\text { study }\end{array}$ & $M R I$ & $C S F$ \\
\hline $1 \mathrm{Fg}$ & $\mathrm{N}$ & $\mathrm{N}$ & $\mathrm{N}$ & $\mathrm{N}$ & $\mathrm{N}$ & $\mathrm{N}$ & A & $\mathrm{N}$ \\
\hline 2 PS & $\mathrm{N}$ & $\mathrm{N}$ & A & $\mathrm{N}$ & A & VSD & $\mathrm{N}$ & A \\
\hline $3 \mathrm{SP}$ & A & A & $\mathrm{N}$ & A & A & $\mathrm{N}$ & A & $\mathrm{N}$ \\
\hline $4 \mathrm{SG}$ & $\mathrm{N}$ & $\mathrm{N}$ & $\mathrm{N}$ & $\mathrm{N}$ & A & VSD & A & $\mathrm{N}$ \\
\hline $5 \mathrm{FL}$ & $\mathrm{N}$ & $\mathrm{N}$ & $\mathrm{N}$ & $\mathrm{N}$ & A & $\mathrm{N}$ & A & $\mathrm{N}$ \\
\hline $6 \mathrm{MA}$ & A & $\mathrm{N}$ & A & $\mathrm{N}$ & A & VSD & A & A \\
\hline $7 \mathrm{SG}$ & A & A & A & A & A & $\mathrm{DH}$ & A & $\mathrm{N}$ \\
\hline $8 \mathrm{RF}$ & A & $\mathrm{N}$ & $\mathrm{N}$ & $\mathrm{N}$ & A & $\mathrm{N}$ & A & A \\
\hline $9 \mathrm{AR}$ & $\mathrm{N}$ & $\mathrm{N}$ & $\mathrm{N}$ & A & A & VSD & $\mathrm{N}$ & $\mathrm{N}$ \\
\hline $10 \mathrm{MP}$ & $\mathrm{N}$ & $\mathrm{N}$ & $\mathrm{N}$ & $\mathrm{N}$ & A & VSD & A & A \\
\hline $11 \mathrm{PP}$ & $\mathrm{N}$ & $\mathrm{N}$ & $\mathrm{N}$ & A & $\mathrm{N}$ & VSD & $\mathrm{N}$ & $\mathrm{N}$ \\
\hline $12 \mathrm{PG}$ & A & A & $\mathrm{N}$ & $\mathrm{N}$ & A & DA & A & A \\
\hline $13 \mathrm{CL}$ & A & $\mathrm{N}$ & A & A & A & $\mathrm{DH}$ & A & A \\
\hline $14 \mathrm{NV}$ & $\mathrm{N}$ & $\mathrm{N}$ & $\mathrm{N}$ & $\mathrm{N}$ & A & VSD & A & A \\
\hline $15 \mathrm{EA}$ & $\mathrm{N}$ & $\mathrm{N}$ & $\mathrm{N}$ & $\mathrm{N}$ & A & $\mathrm{DH}$ & A & A \\
\hline $16 \mathrm{IG}$ & A & A & A & $\mathrm{N}$ & $\mathrm{N}$ & DH & A & $\mathrm{N}$ \\
\hline I. rate & $43.7 \%$ & $25.0 \%$ & $31.2 \%$ & $31.2 \%$ & $87.5 \%$ & $75 \%$ & $81.2 \%$ & $50.0 \%$ \\
\hline
\end{tabular}

I. Rate: Impairment rate; A: Abdominal; N: Normal; VSD: Vesico-sphincter dyssynergia; DH: Detrusor hyper-reflexia; DA: Detrusor areflexia 


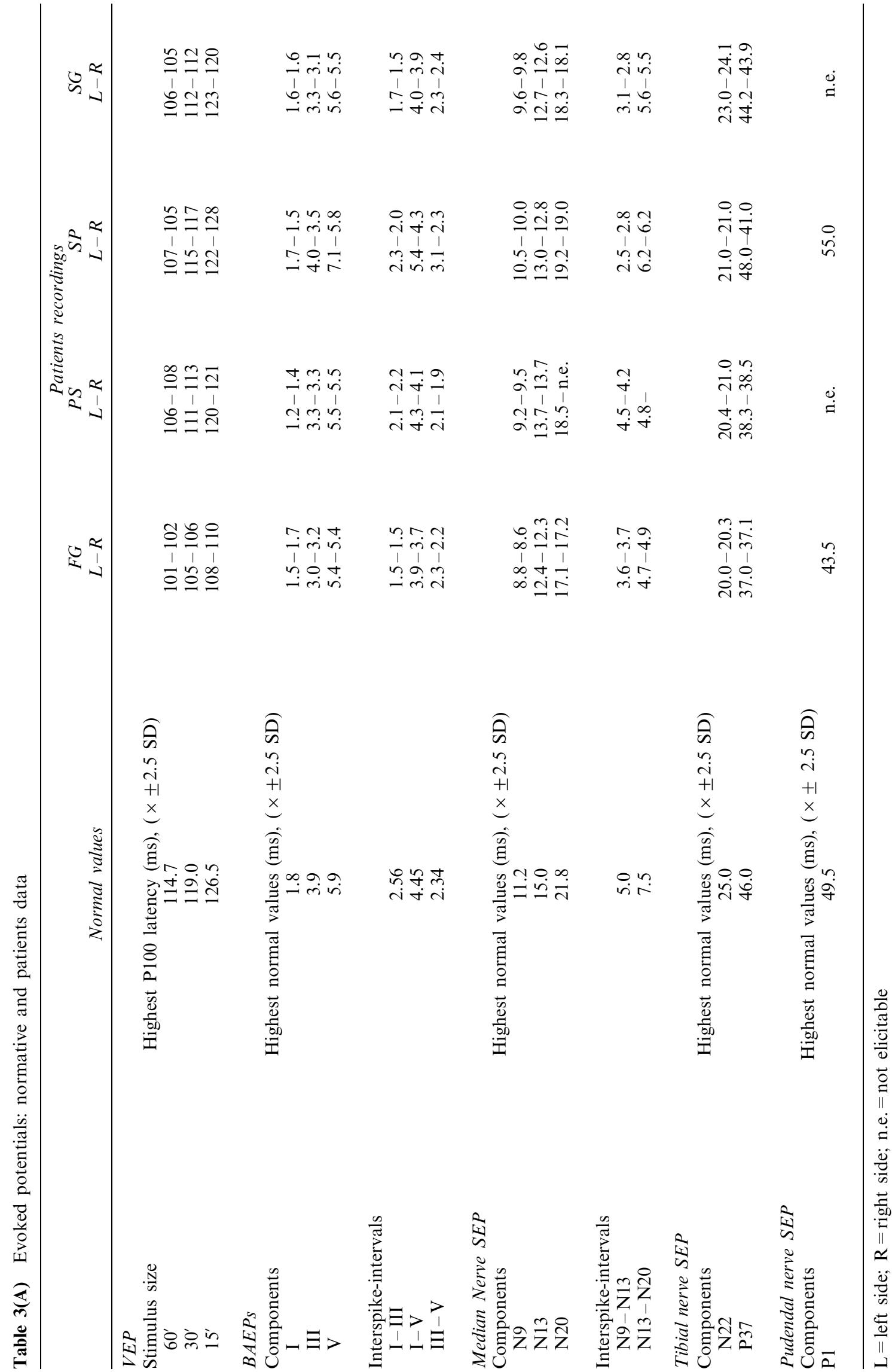




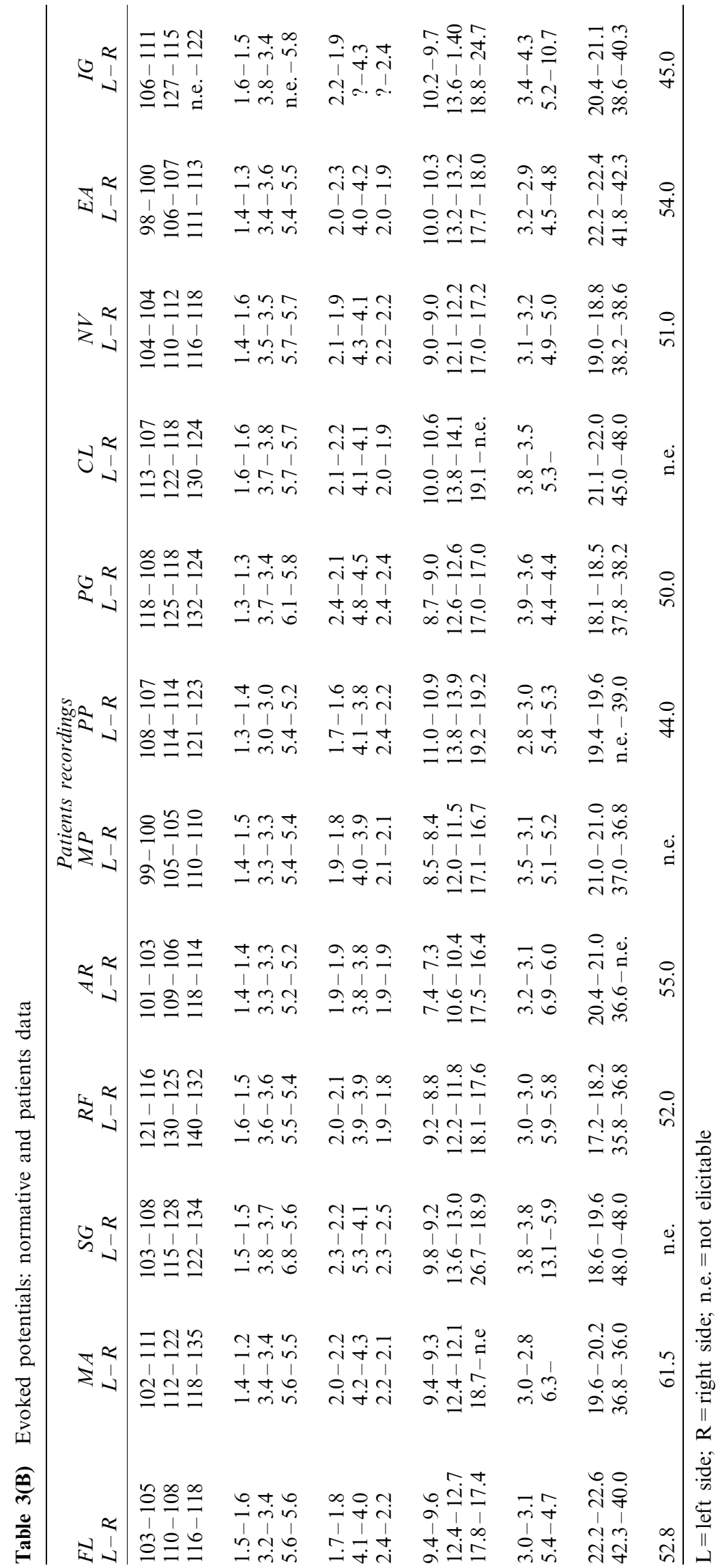


the stage of the disease. pSEP is a worthwhile part of the initial diagnostic evaluation in patients affected by MS, providing information of diagnostic relevance. It helps in screening patients for urodynamic testing which, however, is more specific and by detecting urethrovesical dysfunctions may prevent urological complications.

\section{References}

1 Miller H, Simpson CA, Yeates WK. Bladder dysfunction in multiple sclerosis. Br Med J 1965; 1: $1265-1269$.

2 Blaivas JG, Sinha HP, Zayed AA, Labib KB. Detrusor-external sphincter dyssynergia. J Urol 1981; 125: $542-544$.

3 Blaivas JG, Sinha HP, Zayed AA, Labib KB. Detrusor-external sphincter dyssynergia: a detailed electromyographic study. $J$ Urol 1981; 125: $545-548$.

4 Bradley WE, Logothetis JL, Timm GW. Cystometric and sphincter abnormalities in multiple sclerosis. Neurology 1973; 23: $1131-1139$.

5 Petersen T, Pedersen E. Neurourodynamic evaluation of voiding dysfunction in multiple sclerosis. Acta Neurol Scand 1984; 69: $402-411$.

6 Philp T, Read DJ, Higson RH. The urodynamic characteristics of multiple sclerosis. Br J Urol 1981; 53: 672-675.

7 Oppenheimer DR. The cervical cord in multiple sclerosis. Neuropathol Appl Neurobiol 1978; 4: 151-162.

8 Eardley I et al. Neurophysiology of the striated urethral sphincter in multiple sclerosis. Br J Urol 1991; 68: 81-88.

9 Haldeman S, Bradley WE, Bathia NN, Johnson BK. Pudendal evoked responses. Arch Neurol 1982; 39: 280-283.

10 Tackman W, Porst H, Van Ahlen H. Bulbocavernosus reflex latencies and somatosensory evoked potentials after pudendal nerve stimulation in the diagnosis of impotence. J Neurol 1988; 235: $219-255$.

11 Poser CM et al. New diagnostic for multiple sclerosis: guidelines for research protocols. Ann Neurol 1983; 13: 227-231.

12 Siracusano $\mathrm{S}$ et al. El reflejo bulbocavernoso y el potencial evocado somatosensorial (SEP) del nervio pudendo en la impotencia diabetica. Arch Esp de Urol 1992; 45: 549-551.

13 Lee $\mathrm{KH}$ et al. Magnetic resonance imaging of the head in the diagnosis of multiple sclerosis: a prospective 2-years follow up with comparison of clinical evaluation, evoked potentials, oligoclonal banding and CT. Neurology 1991; 41: 657-660.
14 Kirshner HS, Tsai SI, Runge VM, Price AC. Magnetic resonance imaging and other techniques in the diagnosis of multiple sclerosis. Arch Neurol 1985; 42: 859-863.

15 Chiappa KH. Pattern shift visual, brainstem auditory and shortlatency somatosensory evoked potentials in multiple sclerosis. Neurology 1980; 30: 110-123.

16 Khosbin S, Hallett M. Multimodality evoked potentials and blink reflex in multiple sclerosis. Neurology 1981; 31: 138-144.

17 Kjaer M. Evaluation and graduation of brainstem auditory evoked potentials in patients with neurological disorders. Acta Neurol Scand 1979; 60: $231-242$

18 Hutchinson M, Blandford S, Glynn D, Martin EA. Clinical correlates of abnormal brainstem auditory evoked responses in multiple sclerosis. Acta Neurol Scand 1984; 69: 90-95.

19 Van Buggenhout E, Ketelar P, Carton H. Success and failure of evoked potentials in detecting clinical and subclinical lesions in multiple sclerosis patients. Clin Neurol Neurosurg 1982; 84: 3 14.

20 Becker WJ, Richards IM. Serial pattern shift visual evoked potentials in multiple sclerosis. Canad J Neurol Sci 1984; 11: $53-$ 59.

21 Ghezzi A, Montanini R. Comparative study of visual evoked potentials in spinocerebellar ataxias and multiple sclerosis. Acta Neurol Scand 1985; 71: $252-256$.

22 Muller FA et al. Cerebrospinal fluid immunoglobulins and multiple sclerosis. Correspondence with magnetic resonance imaging and visually evoked potential changes. Arch Neurol 1989; 46: $367-371$

23 Foster DH et al. Visual loss in multiple sclerosis and its relation to previous optic neuritis, disease duration and clinical classification. Brain 1990; 113: $975-987$.

24 Sand T, Sul IA. Evoked potentials and CSF-immunoglobulins in MS: relationship to disease duration, disability, and functional status. Acta Neurol Scand 1990; 82: 217-221.

25 Hammond SR, Yiannikas C. The relevance of contralateral recordings and patient disability to assessment of brainstem auditory evoked potential abnormalities in multiple sclerosis Arch Neurol 1987; 44: $382-387$.

26 Koldewijn EL et al. Relationship between lower urinary tract abnormalities and disease-related parameters in multiple sclerosis. J Urol 1995; 154: 169-173.

27 Amarenco G, Kerdraon J, Denys P. Bladder and sphincter disorders in multiple sclerosis. Clinical, urodynamic and neurophysiological study of 225 cases. Rev Neurol Paris 1995; 151: $722-730$ 